\title{
Two-incision laparoscopic cholecystectomy performed via the "marionette" technique versus conventional laparoscopic cholecystectomy in pediatrics
}

\author{
Mohamed A. Shehata* (D, Abdelmotaleb E. Ebeid and Ashraf A. El Attar
}

\begin{abstract}
Background: Laparoscopic cholecystectomy (LC) has considered the gold standard for the treatment of symptomatic gallstones. The "marionette" technique is a surgical technique for performing a safe, two-incision laparoscopic cholecystectomy without the use of an additional port or any new access devices. This study aimed to compare between the cost and outcome of two incisions LC performed via the marionette technique and the standard LC in pediatrics.

Results: All 32 children with symptomatic cholecystolithiasis were discharged from the hospital in the first postoperative day with no statistically significant difference within days to return to normal work $(p=0.607)$. The operative time in the group (A) which included 16 children who underwent 2 incisions marionette style LC technique was non-significantly longer time $(p=0.184)$ than the group (B) which included 16 children who underwent conventional 4 incisions LC technique. Visual analog scores for pain showed a significant difference between both groups at $6 \mathrm{~h}$ and $12 \mathrm{~h}$ postoperative ( $p=0.000$ and 0.003 , respectively). Overall patient in marionette group was very satisfied by fewer incision and better cosmesis.

Conclusion: Marionette technique performed by an experienced surgeon among pediatric shows a statistically significant cost benefit while maintaining good operative time, less postoperative pain, and more patient's satisfaction and provides excellent aesthetic results.
\end{abstract}

Keywords: Laparoscopic cholecystectomy, Marionette, Operative time, Pediatric

\section{Background}

The surgical world has been changed with the laparoscopic revolution in the 1980s. The first videolaparoscopic cholecystectomy described in the literature was performed by Muhle in 1985 and was met with much opposition [1].

Laparoscopic cholecystectomy (LC) was the gold standard technique for the treatment of symptomatic gallstones. Conventional LC is performed with four trocars. The development of various laparoscopic instruments and techniques has made it possible to reduce the number of trocars [2].

\footnotetext{
* Correspondence: Mohamedshehata81@hotmail.com Department of General Surgery, Pediatric Surgery Section, Faculty of Medicine, Tanta University, El-Geish Street, Tanta 31257, Egypt
}

Single-incision laparoscopic cholecystectomy (SILC) represents a recent technical advancement in minimally invasive surgery [3]. The "marionette" technique was first described by Kuroki et al. in 2011 as a new surgical technique in SILC, for performing a safe, trans-umbilical single-incision, or two-trocar LC without the use of an additional port or any new access devices [4].

Despite the increasing number of marionette laparoscopic cholecystectomies among adults to date, there is a paucity of reports in the literature about this technique in pediatric patients [5].

\section{Methods}

This is a prospective study included 32 children with symptomatic cholecystolithiasis confirmed by ultrasound 
who underwent cholecystectomy at Tanta University Hospitals and its affiliated hospitals, in Tanta, Egypt, between April 2017 and April 2018. The diagnosis was based on history taking, clinical examination, and ultrasound examination. All patients underwent routine investigations preoperatively.

The aim of this study was to compare the cost and outcome of two incisions laparoscopic cholecystectomy performed via the marionette technique and the standard conventional laparoscopic cholecystectomy in pediatrics, including pain control, cosmesis, cost, operative time, and surgeon's ease.

The exclusion criteria included cholangitis, moderate to severe systemic disease (ASA III or more), coagulopathy, patients with the severe chronic pulmonary disease, history of abdominal malignancy, and those with history of upper abdominal surgery (precluding laparoscopic approach).

A full explanation of the procedure was provided to the parents, and informed consent for the procedure was obtained.

The 32 patients were divided into two groups: group A (16 children) included patients who underwent marionette style cholecystectomy technique, and group B (16 children) included those who underwent conventional laparoscopic cholecystectomy technique; each group was done by a surgeon who is expert in the technique.

\section{Surgical procedure}

\section{Anesthesia and positioning for both groups}

Surgery was performed under general anesthesia with the patients in a supine position with a $30^{\circ}$ reversed Trendelenburg position and a left-tilted position 20$30^{\circ}$ (where the left side of the patient is lower than the right one). The operating surgeon and the camera man stood to the left of the patient, and the assistant in cases of conventional laparoscopic cholecystectomy to the right of the patient.

\section{Laparoscopic instruments}

Same standard instruments were used in both groups, including Harmonic scalpel $(\mathrm{J} \& \mathrm{~J})^{\circ}$.

\section{Cannula placement in marionette technique (Fig. 1)}

A semi-lunar incision was performed above the umbilicus along its circumference. Pneumoperitoneum was established with an open cut down technique. A 5/10$\mathrm{mm}$ cannula (according to patient size) was inserted into the incision (and this cannula for the telescope), A low flow rate of $\mathrm{CO}_{2}$ was used initially; increased tympani was confirmed in all four quadrants. Another $5 \mathrm{~mm}$ cannula was inserted on the left side of the telescope cannula (left side of the patient) through the same supraumbilical incision. The left one was slightly above the main cannula (at 2 o'clock). A 3rd cannula $5 / 10 \mathrm{~mm}$ was inserted in the epigastric area slightly below and to the right side of the xiphoid process to be to the right of the falciform ligament of the patient.

\section{Marionette technique}

Used to elevate the fundus and mobilize the Hartmann's pouch to expose the Calot's triangle. A suture was passed through the abdominal wall from outside to inside, passing the gallbladder, and then returned back from inside to outside using the laparoscopic needle holder (Fig. 2). This percutaneous suture (2-0 polypropylene) was passed in the right subcostal region, below the right costal margin, halfway between the midclavicular and anterior axillary line to be stitched to the gallbladder (body \pm Hartmann's pouch) (to achieve adequate retraction and exposure of the gallbladder hilum and the Calot's triangle) (Figs. 2, 3, and 4).

\section{Cannula placement in conventional technique}

The standard technique of performing $\mathrm{LC}$ is to use 4 ports. A $5 / 10 \mathrm{~mm}$ telescope usually a $30^{\circ}$ is used at the supraumbilical incision. Another $5 / 10 \mathrm{~mm}$ trocar is used in the epigastrium which is the main right working port

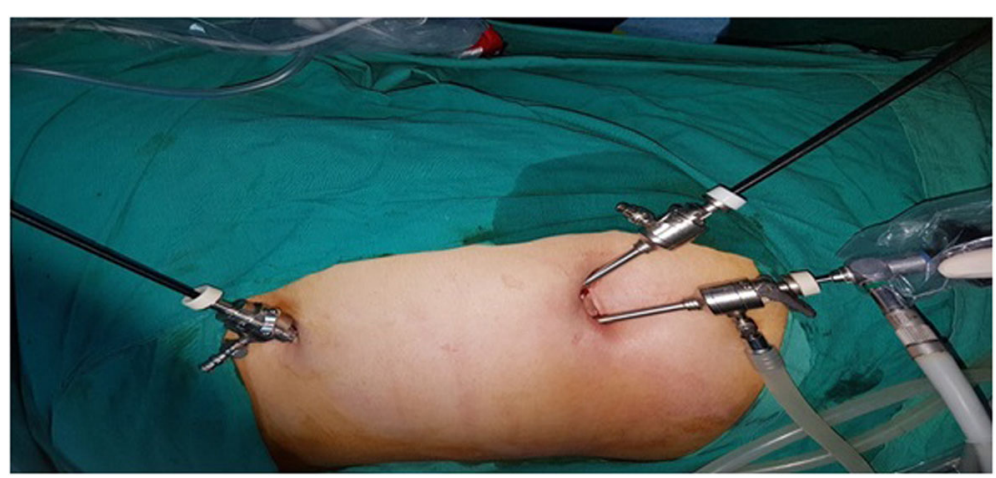

Fig. 1 Cannula placement in marionette technique 


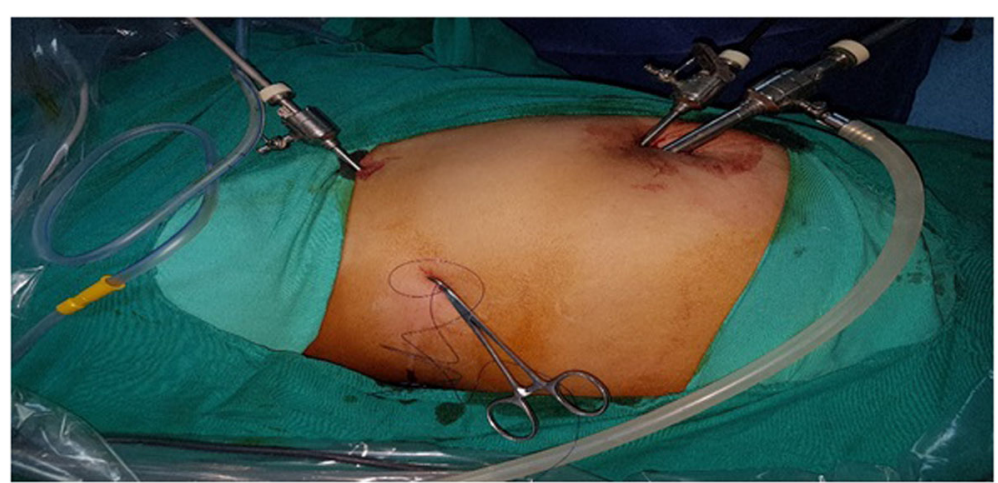

Fig. 2 Suture was passed through the abdominal wall from outside to inside, passing the gall bladder, and then returned back from inside to outside

for the surgeon. One $5 \mathrm{~mm}$ trocar in the right anterior axillary line at the level of the umbilicus is used for gallbladder fundus traction and another $5 \mathrm{~mm}$ trocar in the right hypochondrium/midclavicular line is used as left hand working port for the surgeon. With the left hand, the Hartmann's pouch is retracted and with the righthand right and left leaflets dissection is done in Calot's triangle until safety windows (critical view of safety) are created (Fig. 4).

\section{Outcome assessment}

The primary endpoint for this study was the cost of the procedure. This information was gathered based on operative cost/minute of operating room time as well as the cost of instruments used during the procedure. The difference in instrumentation cost between these two groups primarily involved the difference between trocar and instrument number.

Secondary endpoints in this study included the technique feasibility and safety based on the surgical findings (acute cholecystitis, adhesions, bile spill, and an intrahepatic gallbladder), operative time (defined as the time between skin incision and closure of the last wound), length of hospital stay, postoperative pain, intraoperative blood loss, and postoperative complication rate within the 30-day postoperative period. Patients were followed up for 1 month after the operation. All patients and their parents were reviewed 1 week after surgery to assess their scar satisfaction.

\section{Statistical analysis}

Data analysis was conducted using SPSS (Inc., Chicago, IL, USA). Baseline characteristics were compared between the two groups using $\times 2$ test for categorical variables and $t$ test for continuous variables. $P$ values $\leq 0.05$ indicate statistical significance.

\section{Results}

During this clinical study, 35 patients were thought to be eligible for the study. However, 3 patients were excluded from the study either due to not meeting the inclusion criteria (2 with the previous laparoscopic appendectomy) or due to refusal to participate (1 patient). The remaining 32 patients were randomly allocated into two equal groups. The data of all patients were successfully collected (Fig. 5).

Thirty-two consecutive pediatric patients were recruited for this study, 8 males, and 24 females. They

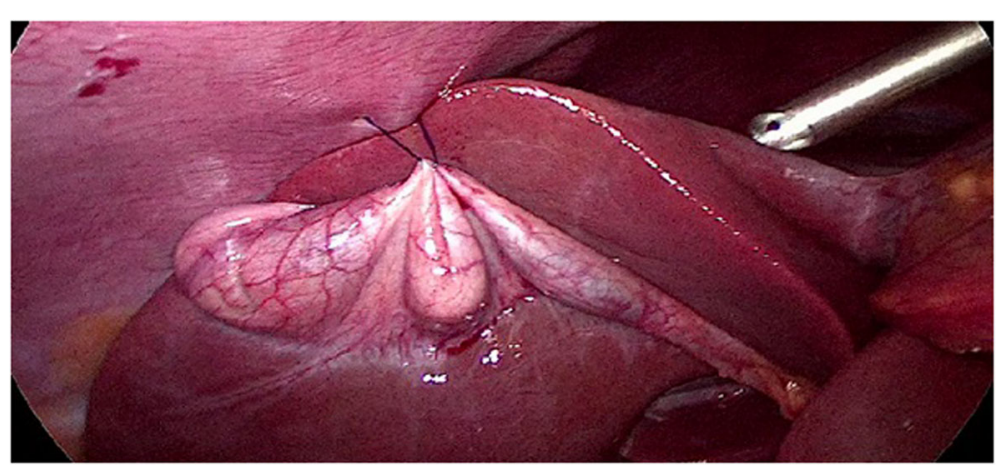

Fig. 3 Percutaneous suture was passed to be stitched to the gallbladder (body/Hartman and body) 


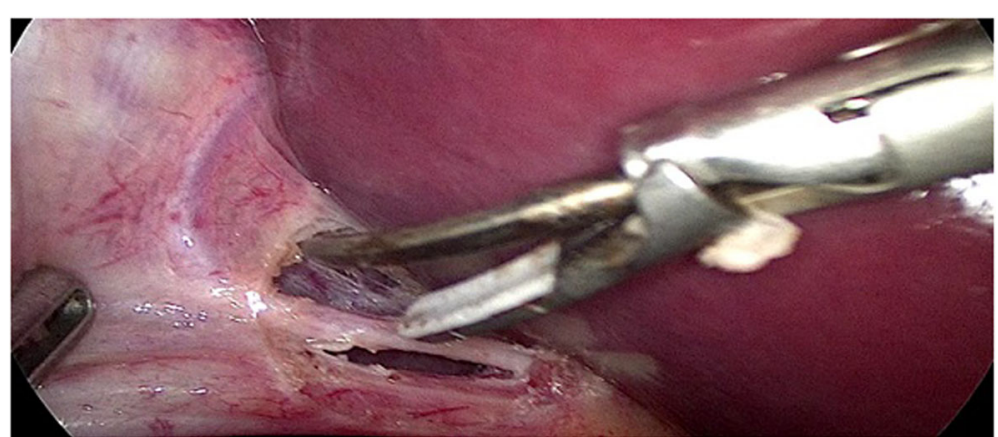

Fig. 4 Critical view of safety

were divided in 2 groups, group (A) comprised 16 patients who underwent laparoscopic cholecystectomy (LC) through the marionette technique by a surgeon who is expert in this technique and group (B) comprised 16 patients who underwent $\mathrm{LC}$ by the conventional method by another surgeon. The demographic data were comparable in both groups (Table 1).

Among the 32 patients included in this study, there were two cases presented with acute cholecystitis (one in each group), and one case with choledocholithiasis in (group A), and 29 cases with chronic calcular cholecystitis (14 in group A and 15 in group B) (Table 2).
In this study, two female patients (one diagnosed as acute cholecystitis aged 8 years and other with chronic cholecystitis aged 3 years) started by the marionette technique but failed to be completed and converted to the conventional LC. In the first case, she was converted after $20 \mathrm{~min}$ of trial due to a difficult surgical procedure due to severe intraperitoneal adhesions and the second case was converted after 8 min due to a narrow intraabdominal space.

The female that was diagnosed with choledocholithiasis aged 17 years. This patient underwent combined endoscopic retrograde cholangiopancreatography (ERCP) and

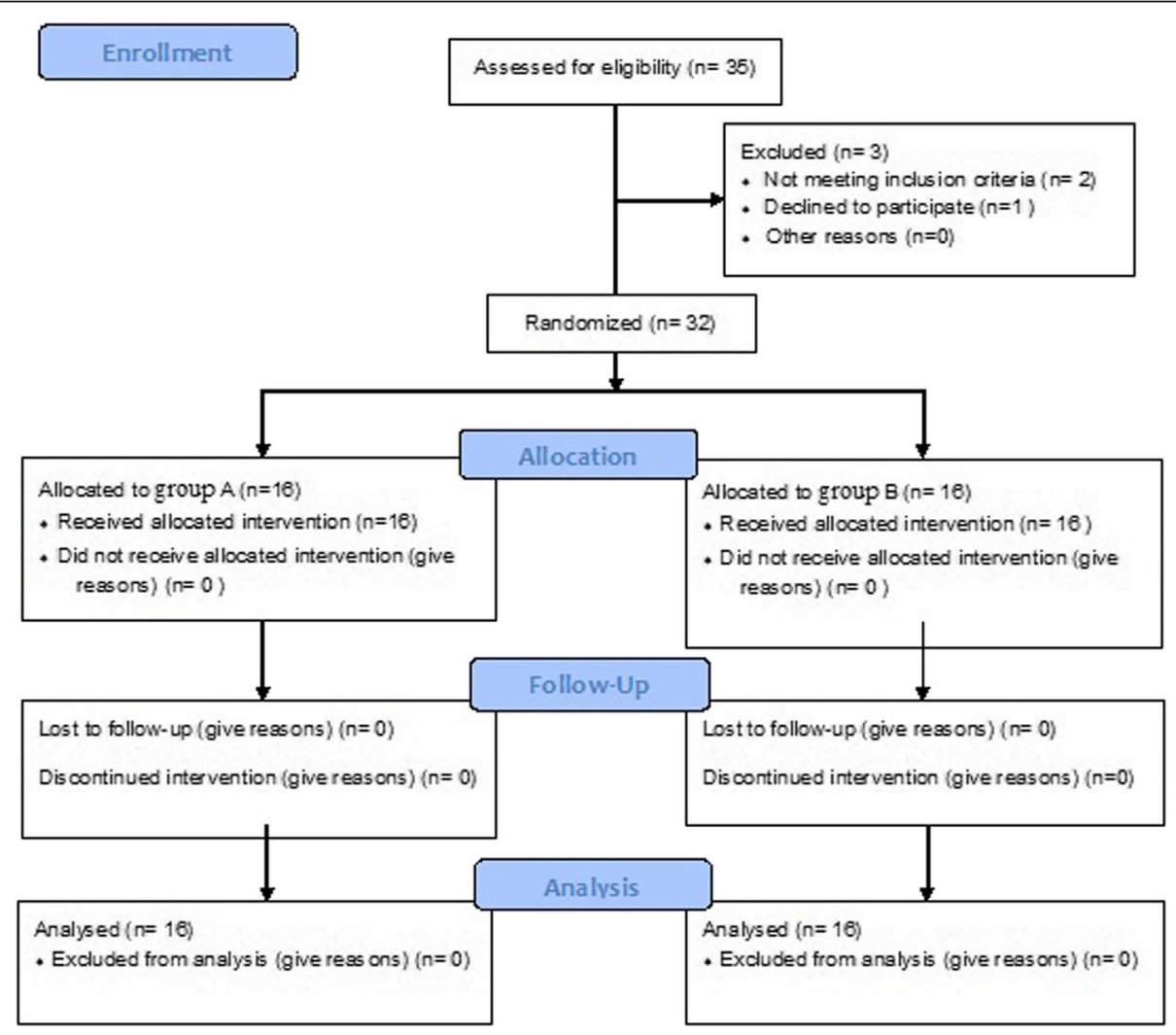

Fig. 5 CONSORT flow chart 
Table 1 Demographic of the two groups

\begin{tabular}{llll}
\hline No of patient (\%) & & Group (A) Marionette group & Group (B) Conventional group \\
& & $16(50 \%)$ & $16(50 \%)$ \\
\hline Gender & Male & $2(12.5 \%)$ & $6(37.5 \%)$ \\
& Female & $14(87.5 \%)$ & $10(62.5 \%)$ \\
& Male: female ratio & $1: 7$ & $1: 1.7$ \\
Age (years) & Range & $3.6-18 \mathrm{yrs.}$ & $3-18 \mathrm{yrs.}$ \\
& Mean \pm SD & $8.1938 \pm 3.57313$ & $8.2125 \pm 5.39640$ \\
BMI & Mean \pm SD & $25.2 \pm 3.4$ & $25.2 \pm 3.4$ \\
ASA (I/II) & & $11 / 5$ & $10 / 6$ \\
\hline BM
\end{tabular}

$B M I$ body mass index, Yrs years, ASA American Society of Anesthesiologists. SD standard deviation

LC in the same setting, the patient was performed successfully by the marionette style.

There was a difference in the cost; as in group A, we used 3 trocars, telescope, 2 instruments, and a stitch; but in group B, we used 4 trocars, telescope, and 3 instruments, so there are extra trocar and instrument in group $\mathrm{B}$ which causes more cost in the conventional LC; this cost increased more if they are disposable more than the reusable instruments (in any case, they are expensive than the stitch). So, the marionette style is cost-effective more than the conventional LC.

All the patients were discharged from the hospital in the first post-operative day, and no one needed a prolonged hospital stay, with no statistically significant difference regarding days to return to normal work between groups $(p=0.607)$. Regarding the operative time, group $\mathrm{B}$ had a non-significantly shorter time $(37.25 \pm 10.3 \mathrm{~min}$ vs. $31.75 \pm 12.4 \mathrm{~min}, p=$ 0.184 ) than group A (Table 3).

Regarding post-operative pain, visual analog scores (VAS) in the postoperative period showed a significant difference in pain in these 2 groups at $6 \mathrm{~h}$ and $12 \mathrm{~h}$ postoperative ( $p=0.000$ and 0.003 , respectively), but later on, the VAS scores were close in the 2 groups showing no statistically significant difference (Table 4).

Overall, there was a similar patient satisfaction on surgery and scars between the two groups as marionette group patients were very satisfied by fewer incisions and better cosmesis (Fig. 6).

\section{Discussion}

Minimally invasive surgery for gallbladder disease has become increasingly popular in pediatric patients, with

Table 2 Clinical presentation

\begin{tabular}{llll}
\hline Clinical presentation & $\begin{array}{l}\text { Group (A) } \\
\text { Marionette group }\end{array}$ & $\begin{array}{l}\text { Group (B) } \\
\text { Conventional } \\
\text { group }\end{array}$ & $p$ value \\
\hline Acute cholecystitis & $1(6.25 \%)$ & $1(6.25 \%)$ & 1.000 \\
Choledocholithiasis & $1(6.25 \%)$ & 0 & \\
Chronic calcular cholecystitis & $14(87.5 \% \%)$ & $15(93.75 \%)$ & \\
\hline
\end{tabular}

advantages of less pain, shorter hospital stays, smaller scars, and quicker return to normal activities [6].

Conventional LC is performed with four trocars. Many surgeons have tried to reduce the number and size of the trocars used in LC in order to reduce the postoperative pain and achieve a more cosmetically satisfactory result [2].

Although several authors have documented the efficacy of single-incision laparoscopic cholecystectomy, there are conflicting concerns regarding increased risks of pain and port-site hernia formation with a larger umbilical incision, bile duct injury, prolonged operative time, and the need for special ports and instruments [7]. Visualization of the critical view is challenging with single-port laparoscopic cholecystectomy as all instruments are in line with the camera and there is reduced the ability to triangulate ports [8].

In this study, we describe a 2I-LC marionette technique that uses three ports and allows for optimal triangulation with two handheld graspers and suture taken on the gallbladder for traction and counter traction to demonstrate the critical view, while minimizing residual scarring and maintaining cosmesis, for multiple types of benign gallbladder disease in children without prolonging operative time or increasing risks of complications and can be converted easily to a traditional 4P-LC if necessary.

In this study, we found that the lower cost was seen with marionette technique basically originated from the lower number of the trocar and less opening of instruments especially if single used ones.

Our study showed that marionette group took a nonsignificantly longer operative time $(5.5 \mathrm{~min}$ more) than the standard technique and early return to work (5.69 vs 5.88 days, respectively), which is much lower than other studies. In Leow et al. study, the mean operative time was $44 \pm 18$ min [9], which was in accordance with times reported in other studies of two-port LCs [10-12]. Poon et al. in his two consecutive studies showed an average operative time of $53 \mathrm{~min}$ in 2002 and $54.6 \pm 24.7 \mathrm{~min}$ in 2002 and 2003 [10, 13]. In Justo-Janeiro et al. study, 
Table 3 Operative time and days to return to normal work

\begin{tabular}{lllll}
\hline Operative results & & Group (A) Marionette group & Group (B) Conventional group & $p$ value \\
\hline Operative time & Range & $24-50 \mathrm{~min}$ & $17-50 \mathrm{~min}$ & 0.184 \\
& Mean \pm SD & $37.25 \pm 10.33 \mathrm{~min}$ & $31.75 \pm 12.45 \mathrm{~min}$ \\
Days to return to normal work (days) & Mean \pm SD & $5.69 \pm 1.13$ & $5.88 \pm 0.88$ & 0.607 \\
\hline
\end{tabular}

$S D$ standard deviation

patients were randomized into 3 groups: LC 1-port using SILC, 2-port LC, and 3-port LC using the standard ports. They found that only the mean operative time was statistically significant, as the 1PLC technique showed a longer duration of the surgery $(p=0.007)$ [14]. In a study conducted by Sabuncuoglu et al., the patients were divided into 3 groups: triple-incision laparoscopic cholecystectomy (TILC), double-incision laparoscopic cholecystectomy (DILC), and single-incision laparoscopic cholecystectomy (SILC). The operation time of the three SILC cases was longer $(100 \pm 17.32 \mathrm{~min}$ and range, 90-120 min) which they thought to be due to the process of gaining experience with SILC, the use of conventional instruments rather than articulated ones and patient-related. In subsequent SILC cases, the operating time was shorter $(73.75 \pm 8.29 \mathrm{~min}$ and range $55-85 \mathrm{~min})$. All the double-incision cholecystectomies were completed in a similar time to those with the 3 -port method $(45.85 \pm 15.59 \mathrm{~min}$ and range $32-125 \mathrm{~min}$ ) [15].

A prospective randomized blinded study by Leung et al. found SILC to take 27 min longer than multiple incisions LC, on average, when surgeon "proficiency was demonstrated by five single-site procedures completed solo" [16]. The difference between our results and theirs' contributed to two incisions in marionette which allowed an easier surgery and better triangulation.

The length of hospital stay in this study was short (1 day). In other studies of two-port LCs, the average postoperative stay was $1-2$ days $[11,13,17]$.

Most of the published studies on SILC use acute cholecystitis as an exclusion criterion while enrolling patients [18]. Antoniou et al. has shown that acute cholecystitis is a predictor of the failure of SILC with a success rate of $59 \%$ (vs $93 \%$ success rate for indications other than acute cholecystitis) [19]. In our study, only one patient with acute cholecystitis 1 $(6.25 \%)$ out of 16 cases aged 8 years in the marionette group failed to be completed and converted to the conventional LC due to difficult surgical procedure caused by severe intraperitoneal adhesion. Although our marionette group had one patient with acute cholecystitis, as it is very rare in our studied group of pediatrics, more cases are required to compare the conversion rate of acute cholecystitis patients with previously published rates of conversion and overall conversion rate for marionette technique.

In Leow et al. study, the total conversion rate from two-incision three port LC was $17 \%$ and consisted of four cases (7\%) of them converted to three-incision four-port LC and six cases (10\%) to open cholecystectomy [9].

An advantage of the marionette over other techniques of conventional LC was the size of the fascial defects created: three $5-\mathrm{mm}$ defects. The conventional LC ports require four defects of $20 \mathrm{~mm}$; small defect and less incision ( 2 skin incision) in our Marionette group are associated with lower VAS among marionette group and subsequent better patient's satisfaction.

According to Justo-Janeiro et al.'s results, pain scores in recovery time showed less pain in the 1PLC, except at 4 and $24 \mathrm{~h}$, and there were no differences. At 5 and 8 days, patients from the 1PLC reported more pain than the 2PLC or 3PLC groups [14]. But Leung et al. has noted no difference between the traditional $\mathrm{LC}$ and single-site LC in the pain severity assessed by visual ana$\log$ scale scores and analgesic use [16].

Table 4 Visual analog scores

\begin{tabular}{|c|c|c|c|c|c|c|c|c|}
\hline Group & & Immediate post-operative & $2 \mathrm{hrs}$ & $4 \mathrm{hrs}$ & $6 \mathrm{hrs}$ & $12 \mathrm{hrs}$ & $18 \mathrm{hrs}$ & $24 \mathrm{hrs}$ \\
\hline \multirow[t]{3}{*}{ A } & Maximum & 3 & 3 & 3 & 4 & 4 & 4 & 4 \\
\hline & Minimum & 2 & 2 & 2 & 3 & 4 & 3 & 3 \\
\hline & Median & 3.00 & 3.00 & 3.00 & 4.00 & 4.00 & 4.00 & 3.00 \\
\hline \multirow[t]{3}{*}{ B } & Maximum & 3 & 3 & 3 & 5 & 5 & 4 & 4 \\
\hline & Minimum & 2 & 2 & 2 & 4 & 4 & 3 & 3 \\
\hline & Median & 3.00 & 2.50 & 2.50 & 4.00 & 4.00 & 4.00 & 3.00 \\
\hline$p$ value & & 0.699 & 0.483 & 0.288 & $0.000^{* *}$ & $0.003^{* *}$ & 0.723 & 0.472 \\
\hline
\end{tabular}

**Denote highly significant. Hrs hours 


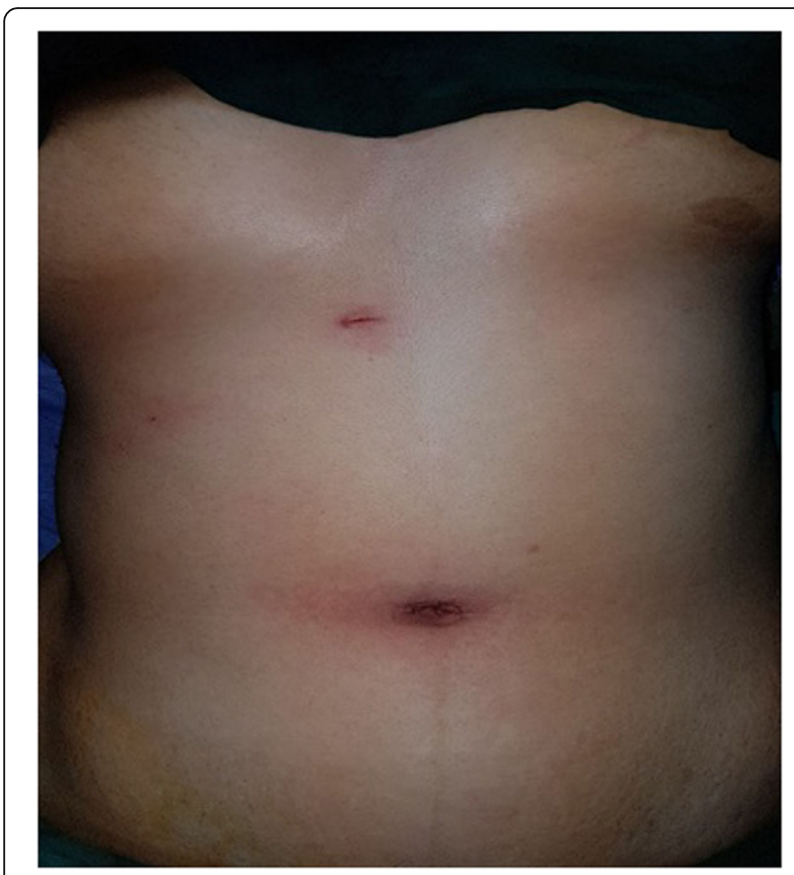

Fig. 6 Immediate wound appearance post marionette

We believe that the improved cosmesis should not be a primary outcome because it is only a natural consequence of decreased port number and does not associate with increasing the risk of intraoperative or postoperative complications. From the aesthetic point of view, the marionette technique is superior to the conventional one, since this involves only two scars (umbilical and epigastric, Fig. 5) with the advantage of avoiding additional two incisions [20]. In some study, cosmesis considered the main outcome; however, there was evidence to support that, the inherent risks of this surgery are increased potentially by the technical difficulty associated with the 1-port technique [21].

In terms of the immediate postoperative complications, no patients in this study developed any complication either early or late as bleeding at the wound edge or a hernia from the supraumbilical wounds. No patient required re-hospitalization because of postoperative complications in Sabuncuoglu et al. study [15]. Similarly, Poon et al. reported a 0\% complication rate in their study [13], whereas in Lee at al.'s study, $6 \%$ of patients had complications and included the intra-abdominal collection, umbilical port site infection, acute urinary retention, and postoperative deranged liver function test due to choledocholithiasis [11]. Bokobza et al. reported in their study of single umbilical incision LC (SUILC) two cases of wound abscess and one case of hemoperitoneum [22].
This study has several limitations. The sample size of the study was small. Also, the limitations of this technique may involve possible bile spillage during placement of suture. This is important if gallbladder carcinoma is incidentally discovered in cholecystectomy for benign disease, an incidence of approximately $0.5 \%$ in adults [23]. Fortunately, gallbladder carcinoma is very rare in pediatrics.

\section{Conclusion}

In conclusion, marionette technique performed by an experienced surgeon on a carefully selected population shows a statistically significant cost benefit, while maintaining good operative time, less postoperative pain, and more patient's satisfaction and provides excellent aesthetic results. Based on our experience, we recommend that 2I-LC marionette technique to be used to reduce scarring in pediatric patients with multiple types of benign gallbladder disease, without significantly increasing operative time or complications with special considerations in younger children because of the discrepancy between the length of the instruments and the size of the peritoneal cavity.

It is important to continue to improve on and push the boundaries of current surgical standards in pediatrics.

\section{Abbreviations \\ $\mathrm{CO}_{2}$ : Carbon dioxide; DILC: Double-incision laparoscopic cholecystectomy; ERCP: Endoscopic retrograde cholangiopancreatography; LC: Laparoscopic cholecystectomy; PLC: Port laparoscopic cholecystectomy; SILC: Single- incision laparoscopic cholecystectomy; SUILC: Single umbilical incision LC; TILC: Triple-incision laparoscopic cholecystectomy; VAS: Visual analog scale}

\section{Acknowledgements}

Not applicable

The committee's reference number 5-3-2017

\section{Authors' contributions}

MAS gave the idea, wrote the paper with revision, and the corresponding author. AEE collected the patients' data and analyzed them. AAE put the study design and followed the patients postoperatively. All authors have read and approved the final version of the manuscript.

\section{Funding}

This study had no funding from any resource.

\section{Availability of data and materials}

The datasets used and/or analyzed during the current study are available from the corresponding author on reasonable request.

\section{Ethics approval and consent to participate}

This study was approved by the Review Board of the Department of General Surgery, Faculty of Medicine, Tanta University, Egypt, on the 4th of March 2017. All patients included in this study gave written informed consent to participate in this research. If the patient was less than 16 years old or unconscious at the time of the study, written informed consent for their participation was given by their parent or legal guardian.

\section{Consent for publication}

All patients included in this research gave written informed consent to publish the data contained within this study. If the patient was less than 16 
years old, deceased, or unconscious when consent for publication was requested, written informed consent for the publication of this data was given by their parent or legal guardian.

\section{Competing interests}

The authors declare that they have no competing interest.

Received: 4 October 2019 Accepted: 23 December 2019

Published online: 03 January 2020

\section{References}

1. Walker RJ. The first laparoscopic cholecystectomy. JSLS. 2001;5:89.

2. Mori T, Ikeda Y, Okamoto K, Sakata K, Ideguchi K, Nakagawa K, et al. A new technique for two-trocar laparoscopic cholecystectomy. Surg Endosc. 2002; 16:589-59.

3. Ponsky TA. Single port laparoscopic cholecystectomy in adults and children: tools and techniques. J Am Coll Surgeons. 2009;209:e1-6.

4. Kuroki T, Adachi T, Kitasato A, Okamoto T, Tajima Y, Kanematsu T. Marionette method for transumbilical single-incision, two-trocar laparoscopic cholecystectomy: a new, simple technique. Hepatogastroenterology. 2011;58:729-31.

5. Oak SN, Parelkar S, Akhtar T, Pathak R, Vishwanath N. Role of laparoscopic cholecystectomy in children. J Indian Asso Ped Surg. 2005;10:92-4.

6. Bignell $M$, Lewis $M$, Cheong $E$, et al. A prospective, randomized, single-blind trial of 5-mm versus 3-mm ports for laparoscopic cholecystectomy: is smaller better? Surg Endosc. 2013;27:3616-21.

7. Alptekin $H$, Yilmaz H, Acar F, Kafali ME, Sahin M. Incisional hernia rate may increase after single-port cholecystectomy. J Laparoendosc Adv S. 2012;22:731-7.

8. Sable SA, Nagral S, Doctor N. Single-incision laparoscopic cholecystectomy is associated with a higher bile duct injury rate. Ann Surg. 2015;261:e79.

9. Leow VM, Faizah MS, Mohd Sharifudin S, Letchumanan V, Yang KF, Manisekar K. Two-incision three-port laparoscopic cholecystectomy. A feasible and safe technique. Med J Malaysia. 2014;69:129-32.

10. Poon C, Chan K, Lee D, Chan K, Ko C, Cheung H, et al. Two-port versus fourport laparoscopic cholecystectomy. Surg Endosc. 2003;17:1624-7.

11. Lee K, Poon C, Leung K, Lee D, Ko C. Two-port needlescopic cholecystectomy: prospective study of 100 cases. Hong Kong Med J. 2005; 11:30-5.

12. Bhattacharya K, Cathrine N. Two port laparoscopic cholecystectomy. Trop Gastroenterol Offic J Dig Dis Foundation. 2000;21:149.

13. Poon C-M, Chan K-W, Ko C-W, Chan K-C, Lee DW, Cheung H-Y, et al. Twoport laparoscopic cholecystectomy: initial results of a modified technique. J Laparoendosc Adv S. 2002;12:259-62.

14. Justo-Janeiro JM, Vincent GT, Vázquez de Lara F, de la Rosa Paredes R, Orozco EP, Vázquez de Lara LG. One, two, or three ports in laparoscopic cholecystectomy? Intl Surg. 2014;99:739-44.

15. Sabuncuoglu MZ, Benzin MF, Cakir T, Sozen I, Sabuncuoglu A. Triple, double- and single-incision laparoscopic cholecystectomy: a prospective study. Int J Clin Exp Med. 2014;7:3385

16. Leung D, Yetasook AK, Carbray J, Butt Z, Hoeger Y, Denham W, et al. Single-incision surgery has higher cost with equivalent pain and quality-of-life scores compared with multiple-incision laparoscopic cholecystectomy: a prospective randomized blinded comparison. J Am Coll Surgeons. 2012;215:702-8.

17. Ramachandran C, Arora V. An innovative new method for gallbladder removal. J Laparoendosc Adv S. 1998;8:303-8.

18. Marks JM, Phillips MS, Tacchino R, Roberts $K$, Onders R, DeNoto G, et al. Single-incision laparoscopic cholecystectomy is associated with improved cosmesis scoring at the cost of significantly higher hernia rates: 1-year results of a prospective randomized, multicenter, singleblinded trial of traditional multiport laparoscopic cholecystectomy vs single-incision laparoscopic cholecystectomy. J Am Coll Surgeons. 2013; 216:1037-47.

19. Antoniou SA, Pointner R, Granderath FA. Single-incision laparoscopic cholecystectomy: a systematic review. Surg Endosc. 2011;25:367-77.

20. Abaid RA, Cecconello I, Zilberstein B. Simplified laparoscopic cholecystectomy with two incisions. Arq Bras Cir Dig. 2014;27:154-6.
21. Bucher P, Pugin F, Buchs N, Ostermann S, Morel P. Randomized clinical trial of laparoendoscopic single-site versus conventional laparoscopic cholecystectomy. Brit J Surg. 2011;98:1695-702.

22. Bokobza B, Valverde A, Magne E, Delaby J, Rubay R, Bellouard A, et al. Single umbilical incision laparoscopic cholecystectomy: initial experience of the coelio club. J Visc Surg. 2010;147:e253-7.

23. Lundberg $\mathrm{O}$, Kristoffersson A. Port site metastases from gallbladder cancer after laparoscopic cholecystectomy. Results of a Swedish survey and review of published reports. Eur J Surg. 1999;165:215-22.

\section{Publisher's Note}

Springer Nature remains neutral with regard to jurisdictional claims in published maps and institutional affiliations.

\section{Submit your manuscript to a SpringerOpen ${ }^{\circ}$ journal and benefit from:}

- Convenient online submission

- Rigorous peer review

- Open access: articles freely available online

High visibility within the field

- Retaining the copyright to your article

Submit your next manuscript at $\boldsymbol{\nabla}$ springeropen.com 